\title{
Synthesis and Characterization of Reduced Graphene Oxide from Indigenous Coal: A Non-Burning Solution
}

\author{
Saud Hashmi ${ }^{1}$, Asim Mushtaq ${ }^{1, *}$, Rafiq Ahmed $^{1}$ and Zaeem Uddin $\mathrm{Ali}^{2}$ \\ ${ }^{1}$ Polymer and Petrochemical Engineering Department, ${ }^{2}$ Chemical Engineering Department, NED University of \\ Engineering \& Technology, Karachi, Sindh, Pakistan
}

\begin{abstract}
A great deal of research has been made into producing graphene or graphene oxide by utilizing graphite as a starting material. An alternate method of producing graphene is using low-grade coal as a starting material. Due to the abundance of coal in Pakistan and increased environmental concern from Government bodies and environmental agencies alike, increased awareness is being made to move over to non-burning solutions to fossil fuels. Experiments were performed on two ranks of coal in parallel; lignite and sub-bituminous. Coal was pretreated first to remove the undesired impurities, which could hinder the graphene synthesis later on. Acid washing with multiple waters was done, followed by carbonization in the furnace. After the pretreatment, the Hummers method was chosen as a chemical process for synthesizing graphene. It is a less complex method, can be easily performed with available resources, and is comparatively cheaper and environmentally friendly. The resulting sample was tested with SEM and EDS, and graphene oxide was confirmed. It was followed by a water-based reduction method to produce reduced graphene oxide from graphene oxide. This modified hydrothermal method was chosen for its eco-friendliness. The final sample was dried and tested with XRD, SEM, FTIR, and RAMAN to authenticate the type of graphene produced. Graphene has remarkable properties, including very high tensile modulus, extremely high thermal conductivity, and charge carrier mobility exceeding $200,000 \mathrm{~cm}^{2} \mathrm{~V}^{-1} \mathrm{~s}^{-1}$. Such properties are reason enough to explore low cost, environment friendly, and scalable means of graphene production. Potential graphene applications in various medical, chemical and industrial processes are enhanced or enabled by using new graphene materials.
\end{abstract}

Keywords: Coal, Graphene graphite, Hummers method, Hydrothermal method, Water-based reduction method.

\section{INTRODUCTION}

Since graphene's discovery in 2004, graphene has been of great attraction to the scientific community. Graphene catches scientific attention due to its fascinating electronic, thermal, mechanical, catalytic, optical, and magnetic properties with great potential in various applications ranging from energy storage, nanocomposite to biomedical materials. It has led to significant interest in the large-scale production of graphene. Many methods have been proposed, including electrochemical exfoliation, graphite exfoliation via intercalates, graphite solvation, arc discharge, unzipping carbon nanotubes, epitaxial growth, chemical vapor deposition, as well as other techniques of chemical oxidation based on the Hummers method [1, 2]. Most of these methods utilize graphite as a starting material because it's rich in carbon content and high purity make it most suitable for graphene synthesis. Undoubtedly, high-quality graphene can be obtained from a graphitic base, making it expensive. There is a need for alternate base material for graphene synthesis, which is relatively cheap and readily available in nature $[3,4]$.

\footnotetext{
"Address correspondence to this author at the Department of Polymer and Petrochemical Engineering, NED University of Engineering \& Technology, Karachi, Sindh, Pakistan. Tel: +92-99261261 Ext: 2419;

E-mail: engrasimmushtaq@yahoo.com
}

Coal is the oldest carbon source known to humankind, extensively used as a solid fuel worldwide, and has the most significant global fossil fuel reserves. The burning of coal is malignant to the environment and the living things, but because coal is so copious and inexpensive, many people are reluctant to give it up as a fuel source. One of the significant downsides of burning coal is that it releases toxins. Coal contains sulfur and other elements, including dangerous metals such as mercury, lead, and arsenic that escape into the environment when it is burned. Burning coal unleashes substantial amounts of carbon dioxide and oxides of sulfur into the atmosphere. These emissions have been shown to increase the greenhouse effect in the atmosphere and global. The reality is that coal is not going away, nor is the growth that spurs its consumption. The challenge is how to utilize coal without these disastrous emissions. Due to the abundance of coal in Pakistan and increased environmental concern from Government bodies and environmental agencies alike, increased awareness is being made to move over to non-burning solutions to fossil fuels [5-7].

The high carbon content and solubilization of minerals in coal can potentially utilize the inherently dirty solid fuel to a source of prestigious carbon nanomaterials such as graphene, graphene quantum dots, or carbon nanotubes. The coal is constituted of 
polycyclic aromatic compounds with 4-5 stacked layers, which are graphene sheets having irregular onion-like arrangements along with other minerals constituents. The presence of these minerals and ash in coal inherently makes it low quality and requires leaching before any application $[8,9]$.

Table 1: Different Studies Regarding Graphene

\begin{tabular}{|c|c|}
\hline Year & Different Studies Regarding GRAPHENE \\
\hline 2014 & $\begin{array}{l}\text { A unique two-step Hummers method for fabricating } \\
\text { low-defect graphene oxide nanoribbons through } \\
\text { exfoliating multiwall carbon nanotubes. }\end{array}$ \\
\hline 2015 & $\begin{array}{l}\text { Graphene oxide and graphene from low-grade coal: } \\
\text { Synthesis, characterization, and applications. }\end{array}$ \\
\hline 2015 & Exfoliation of graphene via wet chemical routes. \\
\hline 2015 & $\begin{array}{l}\text { Formation of single and multi-walled carbon nanotubes } \\
\text { and grapheme from Indian bituminous coal. }\end{array}$ \\
\hline 2015 & $\begin{array}{l}\text { Comparative study of synthesis and reduction methods } \\
\text { for graphene oxide. }\end{array}$ \\
\hline 2016 & $\begin{array}{l}\text { Preparation of fluffy graphene nano-sheets from coal- } \\
\text { tar pitch with nano- } \mathrm{Al}_{2} \mathrm{O}_{3} \text { as filler. }\end{array}$ \\
\hline 2016 & $\begin{array}{l}\text { Eco-friendly synthesis of few-layer graphene with a } \\
\text { high surface area under low temperature for } \\
\text { supercapacitors. }\end{array}$ \\
\hline 2016 & Coal briquette carbonization in a slot-type coke oven. \\
\hline 2016 & $\begin{array}{l}\text { Reduction and structural evolution of graphene oxide } \\
\text { sheets under hydrothermal treatment. }\end{array}$ \\
\hline 2018 & $\begin{array}{l}\text { The electrochemical biosensor was used to estimate } \\
\text { the cytotoxicity of fluorine on the sustainability of MCF- } \\
7 \text { cells. }\end{array}$ \\
\hline 2019 & $\begin{array}{l}\text { Graphene oxide was attained by the Hummers method } \\
\text { and additional encumbered with biologically active } \\
\text { agents. }\end{array}$ \\
\hline 2020 & $\begin{array}{l}\text { Designing reduced graphene oxide-based doped } \\
\text { sample nanocomposites will be an efficient method to } \\
\text { make effective photocatalysts. }\end{array}$ \\
\hline 2021 & $\begin{array}{l}\text { The ultrasonic-assisted chemical activation method is } \\
\text { more effective than other methods to produce activated } \\
\text { carbons from abundant coal resources. }\end{array}$ \\
\hline
\end{tabular}

The primary objective of this research is to explore the possibilities of a non-burning solution for the massive amount of coal available in Pakistan. Also, it aims to look for an alternative that can serve as an energy resource to meet the various energy requirements. The synthesis of graphene from this lowgrade coal of Pakistan seems to be the best choice. The elucidation of the above statement can be given by the numerous advantages linked with this alternative. It will not only eliminate the dangers associated with the combustion of coal, but it will utilize the maximum energy content of coal, which can never be achieved in any other way. So, the sole purpose is to get the maximum benefit out of this fossil fuel before it gets depleted.

Several articles were reviewed before moving forward with this research. Some relevant studies have been listed in Table 1 [4, 9-14]. Some of the common graphene synthesizing processes include; exfoliation (mechanical exfoliation, dispersion of graphite, Hummer's method, substrate preparation) and growth on surfaces (epitaxial growth and chemical vapor deposition) $[15,16]$.

\section{METHODOLOGY}

Graphene has been produced mainly by graphite, but we have taken a different route and researched producing graphene from low-grade coal (lignite coal from Lakhra and sub-bituminous coal from Quetta). Coal has many undesired impurities to be treated first before using it to produce graphene. The elemental impurities are ash content, sulfur content, and volatile matter. Even though the volatile matter is a carbon source, fixed carbon only is needed for graphene formation, so it must be drawn off too. These issues overcome, coal will be acid washed and then repeatedly water washed followed by furnace operation to remove volatile matter. It is the least complex route for pretreatment of coal with all resources in hand. As for the generation of graphene, chemical vapor deposition, as efficient as it is with high yield, was not chosen because it is a complex process and requires an expensive setup. Mechanical exfoliation is uncontrollable and doesn't give a good yield. Hence, to follow a cheaper, less complex route of graphene synthesis, the Hummers method was chosen. The purity of graphene will be compromised, however in this case but its controllability, less complexity, and readily available resources make it a suitable choice for coal-based graphene research. Conventional Hummers method used $\mathrm{NaNO}_{3}$ as a reagent that produces toxic fumes but modified the Hummers method, which is more environmentally friendly [16-18].

Reduce GO into RGO, hydrazine treatment is performed commonly, but that is not eco-friendly. For this study, choose a water-based route that uses environmentally friendly reagents and is very costeffective. The modified hydrothermal method was followed because it is very convenient to use, environmentally friendly, industrially scalable, and shows the ability to recover aromatic structures via repairing the post-reduction defects [19]. 
In this research, the most feasible way to produce carbon nanomaterials from cheap, low-grade lignite and sub-bituminous coal of Pakistan on a large scale is via modified Hummer's method. The as-prepared graphene materials were characterized using X-ray diffraction, Fourier Transform infrared spectroscopy, Scanning electron microscopy, and Energy-dispersive $\mathrm{X}$-ray spectroscopy. The graphene produced from these cheap, low-grade carbon sources resembles the one product from graphite. It is the first attempt to propose the best possible way of manufacturing graphene locally which will open doors to a tremendous variety of applications in energy generation, membranes, composites and coatings, biomedical, sensors, and electronics depending on the structured graphene formed. Not just this, it is also capable of setting up a significant export market of graphene and its products [20, 21]. Low-grade Pakistani subbituminous and lignite coal from the Thar coalfield is used. Nitric acid $(60 \mathrm{v} / \mathrm{v} \%)$ from all the raw materials, with purity level, is given in Table 2 . The following procedure has been devised to produce graphene from indigenous coal (applied on sub-bituminous and lignite coal).

Table 2: Raw Materials with a Purity Level

\begin{tabular}{|c|c|}
\hline Sr. No. & Materials \\
\hline \hline 1 & Sub-bituminous coal \\
\hline 2 & Lignite coal \\
\hline 3 & Poland anthracite coal \\
\hline 4 & Distilled water \\
\hline 5 & Sulfuric acid (98\% conc.) \\
\hline 6 & Hydrogen peroxide (30\% conc.) \\
\hline 7 & Nitric acid $(60 \%$ conc.) \\
\hline 8 & HCL (60\% conc.) \\
\hline 9 & Ethanol \\
\hline 10 & Nitrogen gas \\
\hline 11 & Crushed ice \\
\hline 12 & KMnO $_{4}$ \\
\hline
\end{tabular}

\section{Pretreatment of Coal}

Indigenous coal of Pakistan (sub-bituminous and lignite), being the focus of this research, was used to produce graphene. In comparison with the traditional raw material like graphite, coal is a raw source of carbon with many impurities such as silicon compounds and sulfur compounds. In addition to this, the volatile matter and moisture content of coal is not only futile to graphene synthesis but could also hinder the process. Hence, coal must be pretreated first, rode of these unwanted substances, to get a much purer source of fixed carbon for graphene synthesis. Pretreatment of coal has been divided into three steps. Raw coal (air-dried coal from the mine) was crushed manually to reduce its size to an average of $0.5-1 \mathrm{~cm}$ in diameter. It was followed by a more effective hammer milling, after which it transformed large coal particles into powder. On performing the sieve analysis, a mode size of 90 microns was noted.

For reducing the ash (silicon and iron compounds precisely) and sulfur content of coal, 1 liter of $30 \%$ by volume of $\mathrm{HNO}_{3}$ for every $\mathrm{kg}$ of coal was added and agitated thoroughly. The reaction was highly exothermic, and large amounts of steam and nitrogen oxides were generated. Acid washing ensures that metallic impurities react with nitric acid to produce water-soluble nitrates that could be easily washed away with water. Pyritic and most of the organic sulfur present in coal are oxidized, making them watersoluble and their removal easier. The acid also oxidizes a part of the indigenous coal (brown coal in Pakistan) into humic acid analogous to graphene. The resulting solid is water washed repeatedly using 7 liters of distilled water for every $\mathrm{kg}$ of coal. After adding water, it was left for sedimentation and filtered subsequently. Water washing was repeated (approximately 15 times) until the $\mathrm{pH}$ of the filtrate increased to 6.5 , ensuring that the acid traces and the impurities had been washed away. Proximate analysis of coal was performed before and after washing, and a drop in the percentage of ash and sulfur content could be observed.

After lowering the sulfur and ash content, volatile matter and moisture content were removed by carbonizing coal in a muffle furnace. This process is commonly carried out in a quartz tube furnace to ensure a continuous flow of inert gas. A different approach was devised, and the available muffle furnace in the laboratory was engineered accordingly to serve the same purpose. An inert environment was provided inside the furnace chamber with a continuous nitrogen gas flow from the top opening, maintaining a constant pressure of 2 bar (higher than the atmosphere pressure). The opening at the back of the furnace served as exhaust, and the positive pressure inside ensured that no air (oxygen) entered inside the chamber. A target temperature of $900^{\circ} \mathrm{C}$ was selected because the unbounded coal moisture draws off completely at $150^{\circ} \mathrm{C}$, and volatile matter in indigenous coal is known to liberate between $700^{\circ} \mathrm{C}-800^{\circ} \mathrm{C}$. Firstly, 
the sample was weighed in porcelain cups and put inside the furnace with lids on. It is done so that the volatile matter in coal sticks to the inner side of lids and is hence easily removed. The chamber was closed, and a continuous flow of nitrogen was provided. After 15 minutes, the heater was turned on, and the target temperature was set at $900^{\circ} \mathrm{C}$. After this temperature was achieved, the sample was heated for two hours, ensuring the inert environment was maintained inside throughout this time. After two hours, the furnace was switched off and allowed to cool down. Nitrogen flow must be provided until the temperature drops down well below the ignition temperature of the respective coal to avoid combustion. The sample was weighed and analyzed via proximate analysis. A drop in the percentage of volatile matter and moisture content was observed. A rich fixed carbon source was attained after the pretreatment, which can now be further used for graphene production.

\section{Oxidation}

Several processes can produce graphene, but the Hummers method is readily used to generate graphene oxide due to its economic feasibility and reliability. In our research, we have used an improved Hummers method that does not utilize $\mathrm{NaNO}_{3}$ like in conventional hummers, hence decreasing the cost and environmental duty of graphene oxide production [18, 22]. The Hummers method uses sulfuric acid with potassium permanganate as a catalyst because it is a strong oxidizer that attaches many oxygen-containing functional groups to carbon sheets. Implementing functional groups overcomes the inter sheet van der Waals force and enlarges the interlayer spacing. The sheets in such an expanded structure are then easily pulled open using an external force such as sonication. The expanded carbon is exfoliated into multi-layered or even single-layered sheets. These are GO (graphene oxide) sheets that can be further reduced to RGO (reduced graphene oxide).

The $6.0 \mathrm{~g}$ of coal was weighed and taken in a round bottom flask, kept in an ice bath to maintain the flask temperature well below $20^{\circ} \mathrm{C}$. The oxidation process is highly exothermic, and flask temperature must not exceed $20^{\circ} \mathrm{C}$. $150 \mathrm{ml}$ of $98 \% \mathrm{H}_{2} \mathrm{SO}_{4}$ was added to the flask, followed by the slow addition of $18 \mathrm{~g}$ of $\mathrm{KMnO}_{4}$ (in 1.5 hours). $\mathrm{KMnO}_{4}$ must be added very slowly in the reaction mixture ( $1 \mathrm{~g}$ after every 5 minutes) to avoid producing violent, toxic fumes due to a sudden rise in reaction temperature. All this time, the reaction mixture must be vigorously stirred. The flask was then transferred to an oil bath of $60^{\circ} \mathrm{C}$ and, under vigorous agitation, was kept for 7 hours. After this, the heater was switched off, and under continuous agitation, 100 $\mathrm{ml}$ of distilled water was added, and the flask was kept to cool down for half-hour. The mixture was then poured into a beaker with $700 \mathrm{ml}$ of distilled water at $18^{\circ} \mathrm{C}$, and $30 \mathrm{ml}$ of $\mathrm{H}_{2} \mathrm{O}_{2}(30 \%$ by volume) was poured in slowly. $\mathrm{H}_{2} \mathrm{O}_{2}$ reduces the excess $\mathrm{KMnO}_{4}$ and stops the oxidation reaction. As a result, graphene oxide suspension is obtained.

Now, to separate these suspended particles, vacuum filtration of the suspension was performed, passing it through a 0.45 -micron filter paper. The filer paper was dipped in a solvent (ethanol used) because this causes the paper to adhere to the plate and keeps materials from passing under the paper during filtration. The suspension was then filtered once and then washed once with $250 \mathrm{ml}$ of $10 \%$ by volume of $\mathrm{HCl}$. The collected residue was then repeatedly water washed (approximately eight times) till the filtrate $\mathrm{pH}$ increased up to 6.5 . The $500 \mathrm{ml}$ of distilled water was used in one wash. The resulting solid was diluted and sonicated for 30 minutes in an ultrasonic bath for exfoliation into graphene oxide. This $\mathrm{GO}$ dispersion was centrifuged at $3000 \mathrm{rpm}$ for 45 minutes to remove the unexfoliated particles. The settled GO was air-dried for a day and then tested with SEM (Scanning Electron Microscopy) to verify the generation of graphene oxide.

\section{Reduction}

After the GO preparation, a method is to be selected to reduce it to RGO. Hydrazine treatment is largely used for the reduction. Still, it produces toxic fumes, and with the world moving towards eco-friendly processes, a hydrothermal method has been devised to solve this problem. This "water-based" route is advantageous to conventional chemical reduction processes based on hydrazine treatment. Because it is very convenient to use, environmentally friendly, and industrially scalable, and shows the ability to recover aromatic structures via repairing the post-reduction defects. A modified hydrothermal method was used in which GO powder was added to water to form brown dispersions. The $\mathrm{pH}$ of water is maintained at 11 by the addition of $\mathrm{NaOH}$. A nanoparticle synthesis cylinder is cleansed first in a sonication bath for 15 minutes, and then the dispersion is poured into it. This cylinder was then put into an oven under pressure and heated at $245^{\circ} \mathrm{C}$ for 8 hours. For a faster and efficient reaction, the mixture must be stirred continuously. After the reaction, the solid was washed with water several times 
until the $\mathrm{pH}$ of the filtrate normalized to neutral. $500 \mathrm{ml}$ of water was used in each wash. The resulting solid was dried and tested with SEM, FTIR, and XRD to authenticate the generation of reduced graphene oxide. After the test results, RGO was characterized, properties were tested, and further applications were listed accordingly.

\section{RESULT AND DISCUSSION}

\section{Proximate Analysis Before and After Acid Washing}

As shown in Figure 1(a), the particle size distribution shows that the mode particle size is about 90 microns. Violent fumes were observed when acid was added to grinded coal. The acid reacted with metallic minerals and some other impurities. The reaction was highly exothermic. Figure $\mathbf{1}(\mathbf{b})$ shows the rise in $\mathrm{pH}$ with successive washing and stabilizing the $\mathrm{pH}$ around the fifteenth wash. It indicates that virtually all the undesired elements were removed as filtrate $[21,23]$.

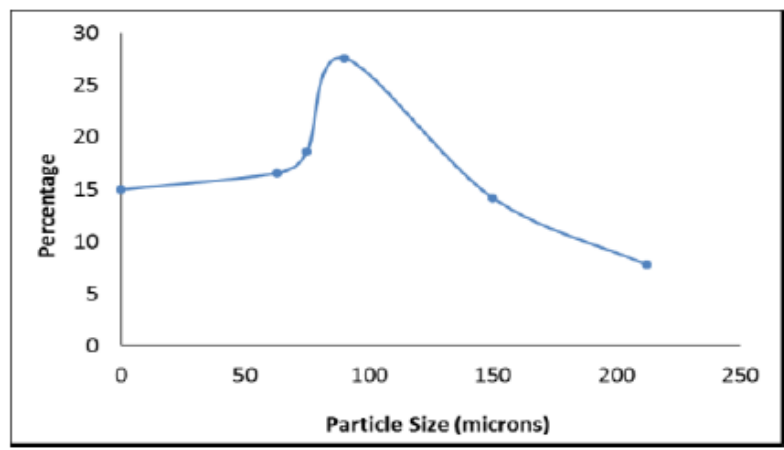

(a)

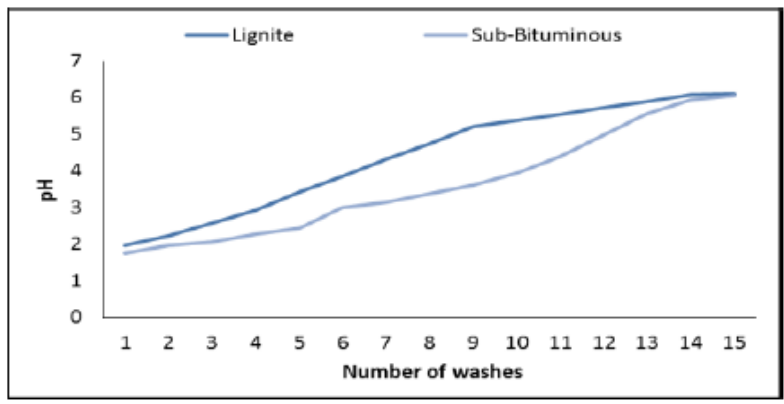

(b)

Figure 1: (a) Particle size distribution of grinded coal (b) $\mathrm{pH}$ rise with successive washing.

\section{Discoloration of Filtrate upon Successive Washing}

The color of the filtrate gradually became paler with each wash, signifying that the dissolved metallic materials and other unwanted impurities were being removed through the filtrate, as shown in Figure 2.

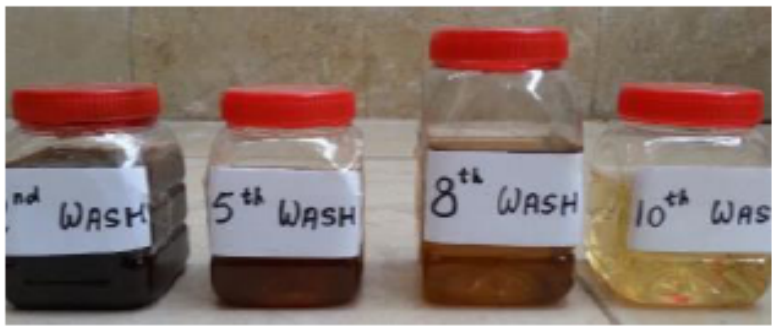

Figure 2: Discoloration filtrate upon successive washing.

The proximate analyses in Figure 3(a) show a significant decrease in the ash content of lignite coal. The percentage ash content reduces from about a whopping $54 \%$ to $21 \%$ [24].

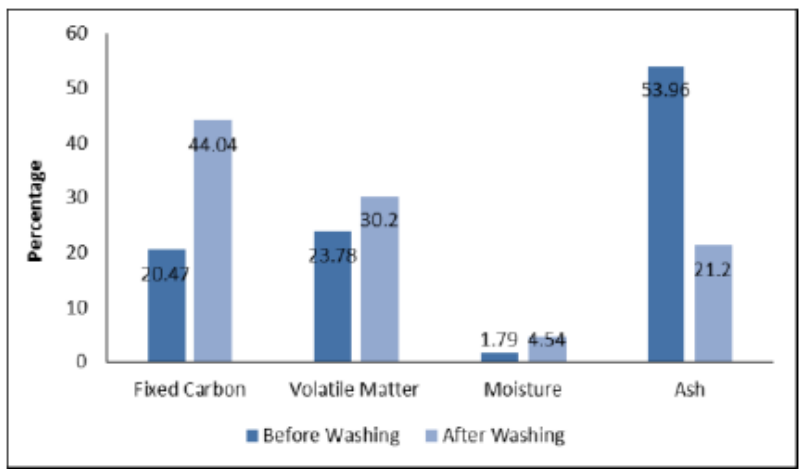

(a)

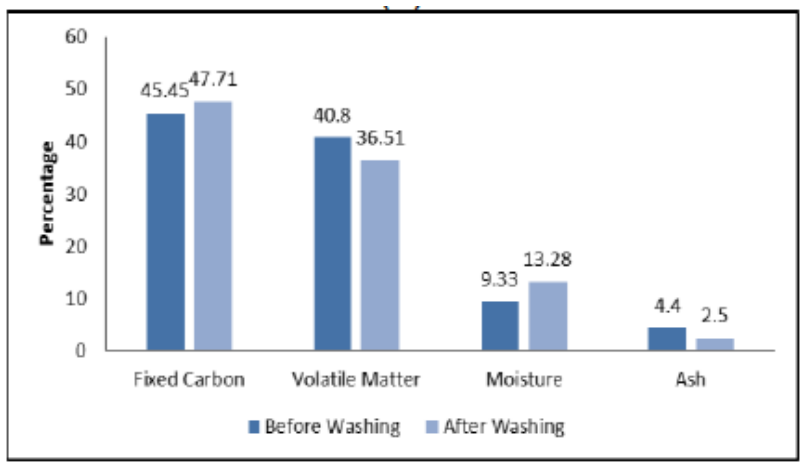

(b)

Figure 3: Proximate analysis before and after washing (a) lignite coal (b) sub-bituminous coal.

Similar results were observed with the subbituminous coal, as presented in Figure 3(b). The ash content reduced, albeit insignificantly because the ash content in the sub-bituminous coal was negligible to begin with $[25,26]$. The proximate analyses before and after furnace operation for both lignite and subbituminous coal show a drastic increase in carbon 
content due to the removal of volatile matter. Figure $\mathbf{4}(\mathbf{a}, \mathbf{b})$ shows these results.

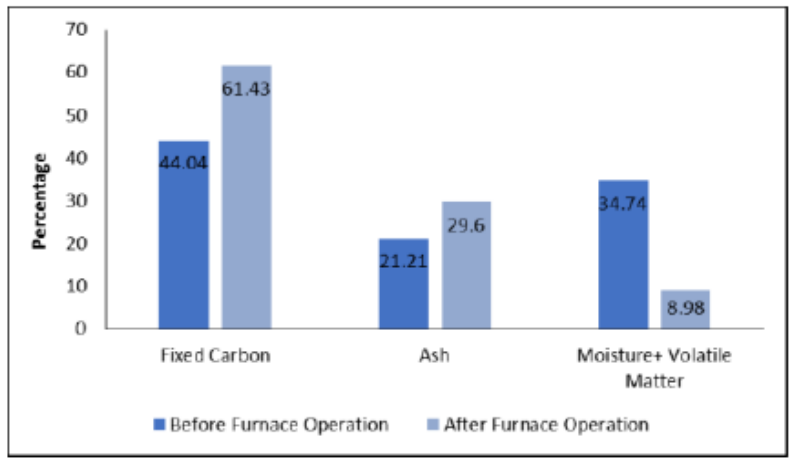

(a)

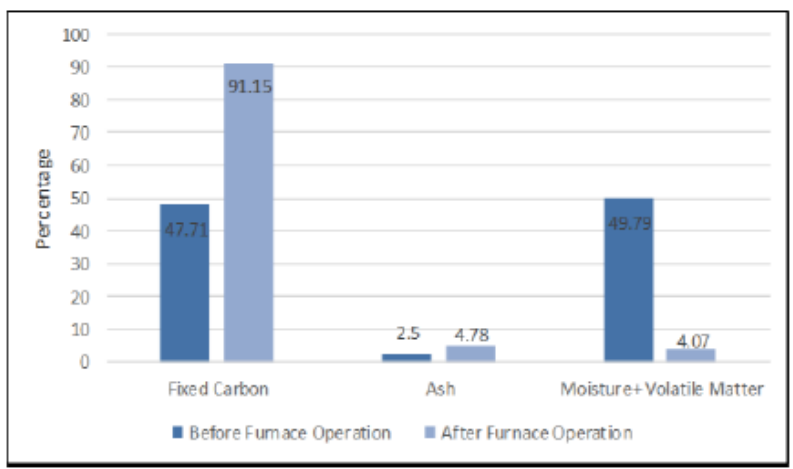

(b)

Figure 4: Proximate analysis before and after furnace operation (a) lignite coal (b) sub-bituminous coal.

\section{SEM Images of Sub-Bituminous Coal Before and After Oxidation}

In Figure 5(a, b), which shows the SEM results of the coal before oxidation and after pretreatment, a large number of pores are visible. This coal, after pretreatment and before oxidation, was porous with macropores greater than $1 \mu \mathrm{m}$. It is known that lowgrade coal like lignite and sub-bituminous have primary porosity with macropores, as confirmed by SEM testing.

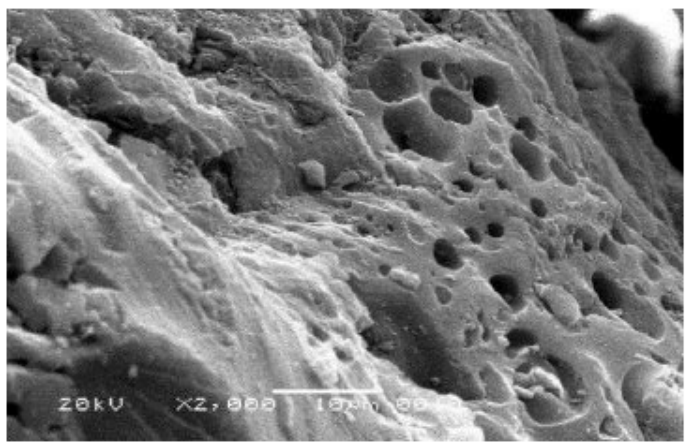

(a)

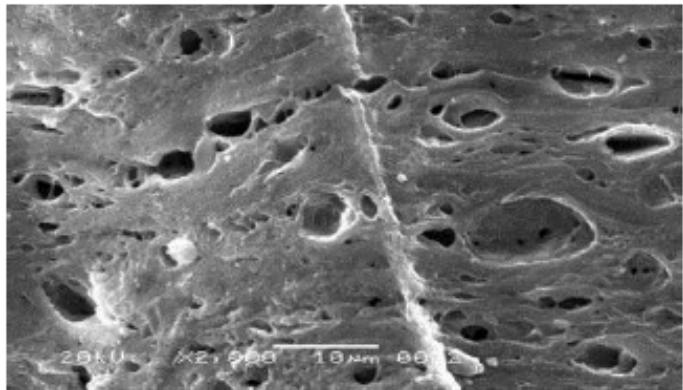

(b)

Figure 5: SEM image of sub-bituminous coal (a) before oxidation (b) after pretreatment.

Figure $\mathbf{6}(\mathbf{a}, \mathbf{b})$ are the zoomed-in SEM images of sub-bituminous. These images show many layers of graphene oxide that are formed after the process of oxidation. The lumped porous coal has now been converted into thin sheets and layers of graphene oxide, as visible in the above images. However, the pores are still visible, indicating that graphene oxide is also porous [10, 26].

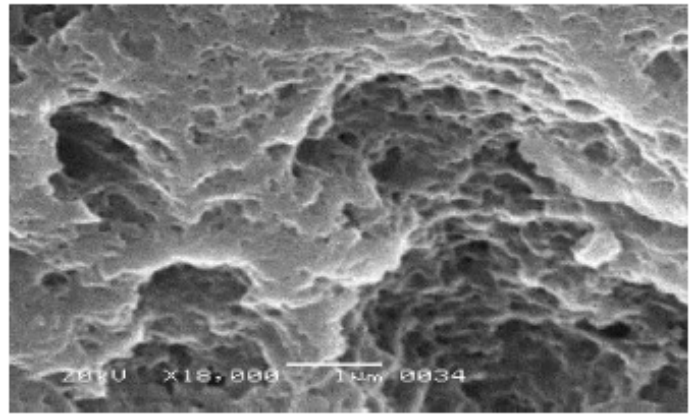

(a)

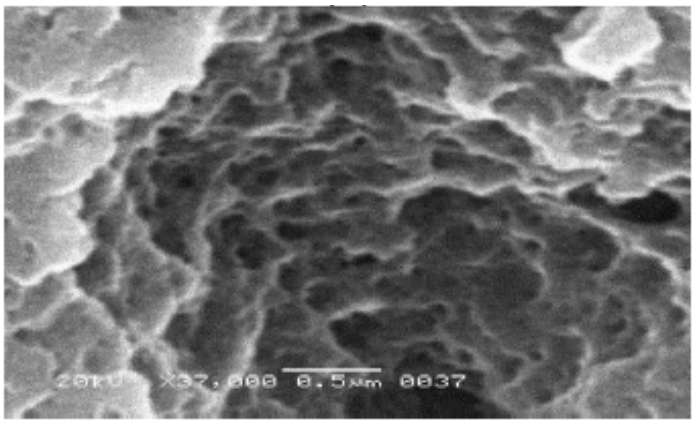

(b)

Figure 6: SEM image of sub-bituminous coal after oxidation (a) $1 \mu \mathrm{m}$ (b) $0.5 \mu \mathrm{m}$.

\section{SEM Images of Sub-Bituminous Coal After Reduction}

The SEM images in Figure 7(a, b) clearly show that after reduction, the reduced graphene oxide layers have exfoliated more, and RGO sheets are quite visible. However, the amorphous RGO was 
synthesized from porous coal instead of crystalline graphite $[4,24]$.

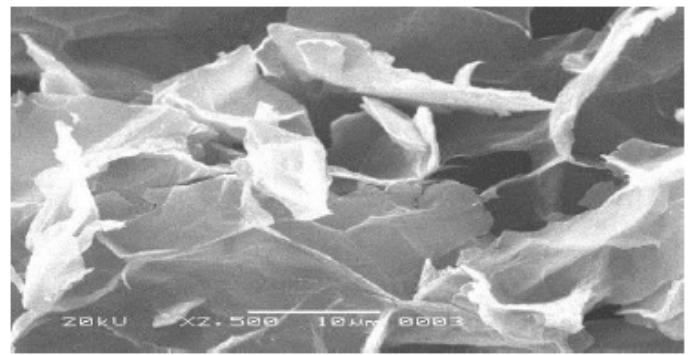

(a)

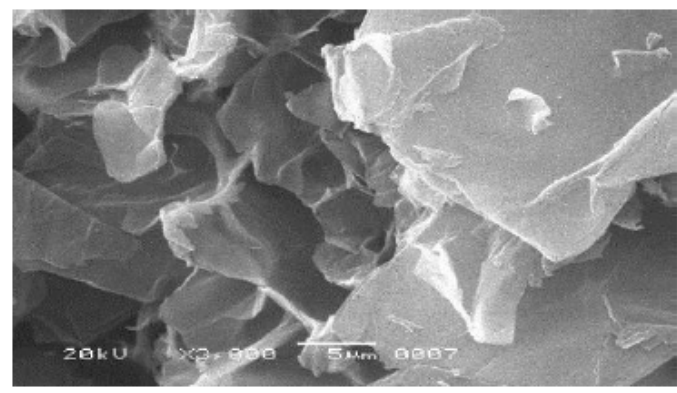

(b)

Figure 7: SEM image of sub-bituminous coal after reduction (a) at $10 \mu \mathrm{m}$ (b) at $5 \mu \mathrm{m}$.

\section{Electron Dispersion Spectroscopy (EDS) of Sub- Bituminous Coal}

Figure $8(\mathbf{a}, \mathbf{b})$ shows the EDS of sub-bituminous coal before and after oxidation. Figure 8 (c) shows the EDS of sub-bituminous coal after reduction.

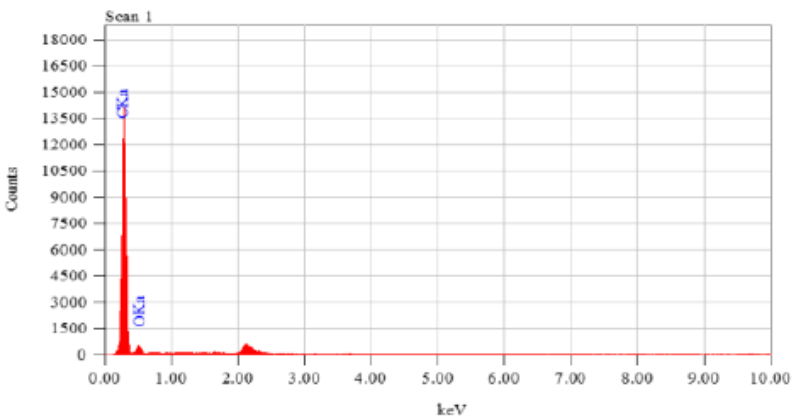

(a)

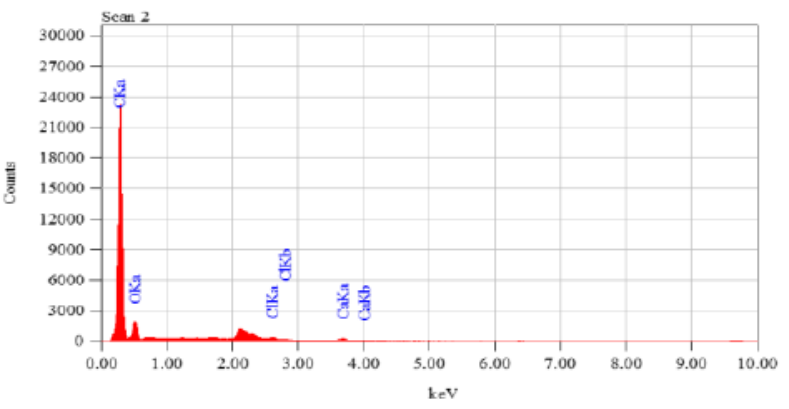

(b)

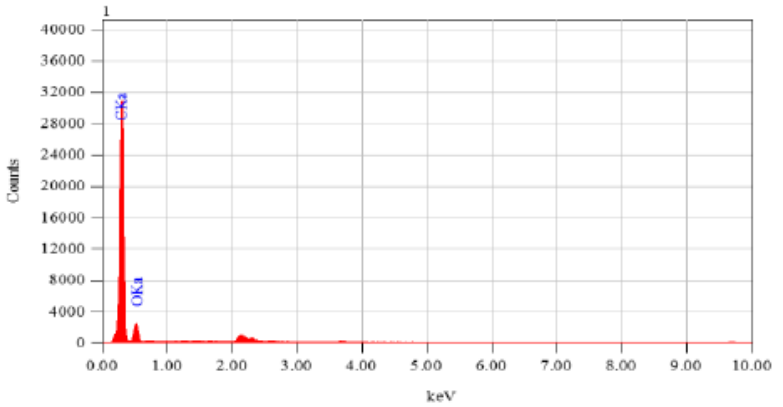

(c)

Figure 8: EDS of sub-bituminous coal (a) before oxidation (b) after oxidation (c) after reduction.

Figure 9(a) shows that the mass percentage of oxygen had a noticeable increase after oxidation, from 15.31 to 23.5 . Hence, the overall percentage of carbon decreased from 84.69 to 75.81 , decreasing the carbon to oxygen ratio from 5.53 to 3.22 . However, there are some traces of copper and calcium seen in the EDS of sub-bituminous after oxidation. It could be because it is highly likely that the $\mathrm{KMnO}_{4}$ we used for oxidation might have had copper and calcium traces in it as impurities [25].

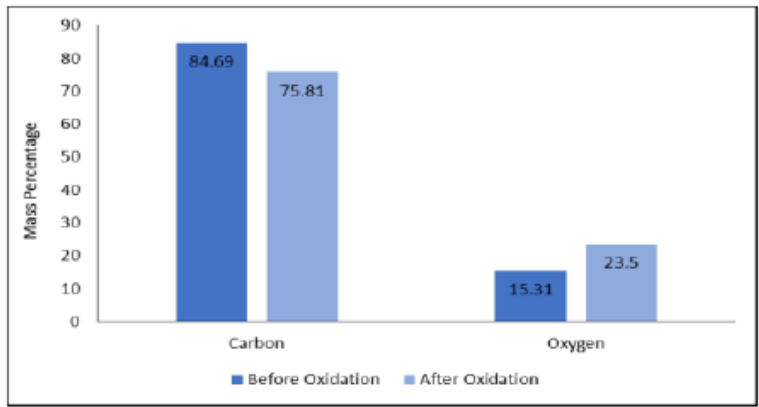

(a)

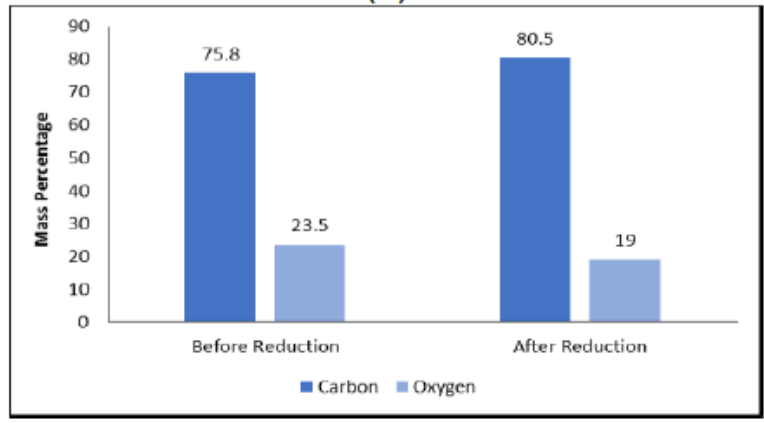

(b)

Figure 9: Mass percentage comparison of carbon and oxygen of sub-bituminous coal (a) before and after oxidation (b) before and after reduction.

Comparing Figure 9(b) explains that the mass percentage of oxygen had a noticeable decrease from 23.5 to 19 . Hence, the overall percentage of carbon increased from 75.8 to 80.5 , increasing the carbon to 
oxygen ratio from 3.22 to 4.23 . It tells that the sample has been reduced and successfully produced RGO from GO.

\section{SEM Images of Lignite Coal Before and After Oxidation}

The lignite coal from Lakhra is low-grade coal with very low carbon content. It has many impurities and is porous with a primary porosity of macropores (greater than $1 \mathrm{um})$, as clearly visible in Figure $\mathbf{1 0}(\mathbf{a}, \mathbf{b})$.

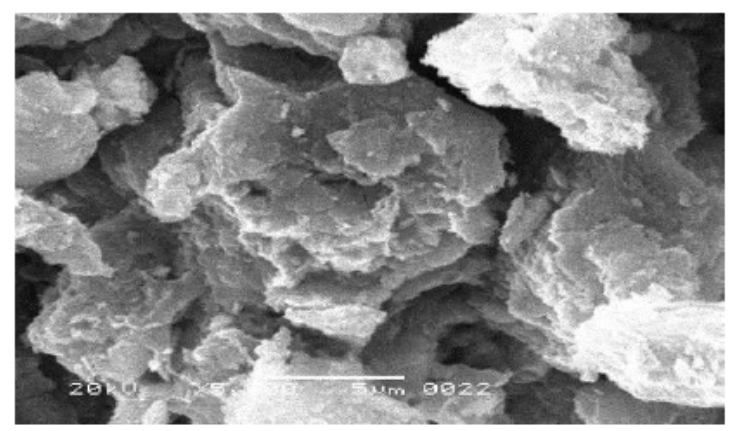

(a)

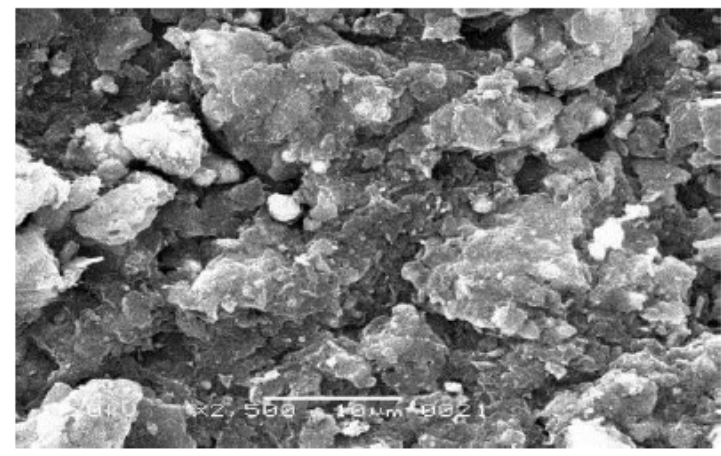

(b)

Figure 10: SEM image of lignite coal before oxidation (a) $5 \mu \mathrm{m}$ (b) $10 \mu \mathrm{m}$.

It is shown from Figure 11(a, b) that lignite after oxidation has been exfoliated, although it has a lot of impurities which is why it didn't show the proper multilayered structure and is instead in the form of flakes. This graphene oxide (GO) is flaky and amorphous [1].

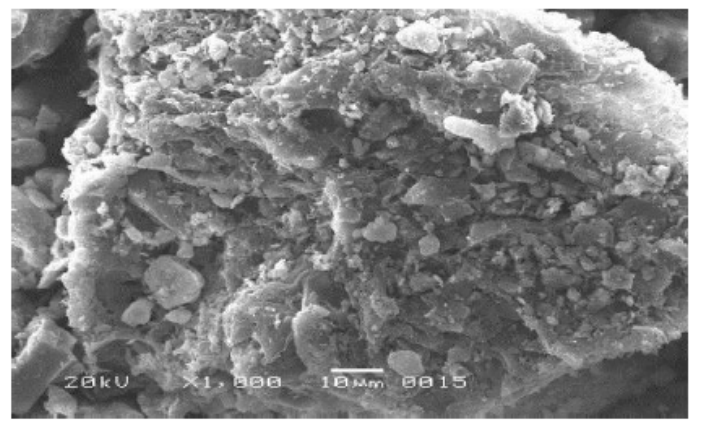

(a)

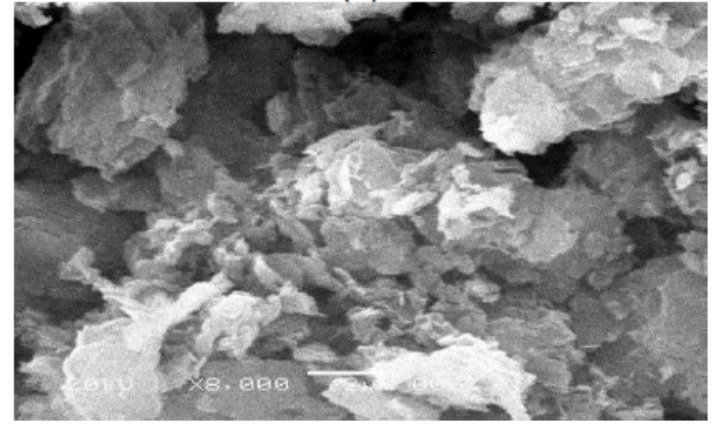

(b)

Figure 11: SEM image of lignite coal after oxidation (a) $10 \mu \mathrm{m}$ (b) $2 \mu \mathrm{m}$.

\section{SEM Images of Lignite Coal after Reduction}

Figure 12(a, b) of lignite coal did not show a noticeable structural change; however, observing it, flaky $\mathrm{GO}$ has been exfoliated more after reduction. EDS of reduced graphene oxide from lignite, however, more confirms the reduction process.

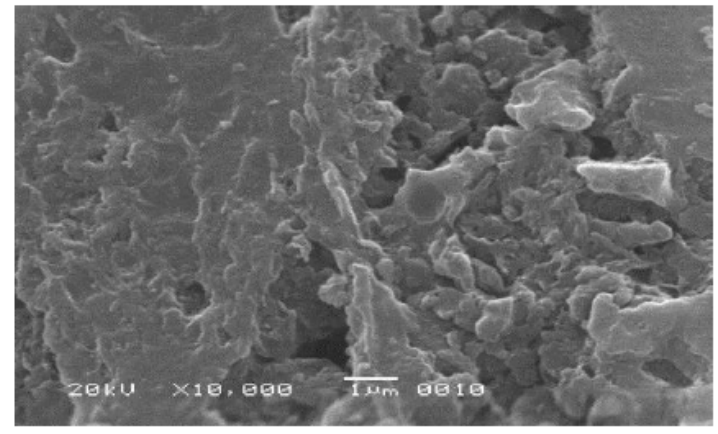

(a)

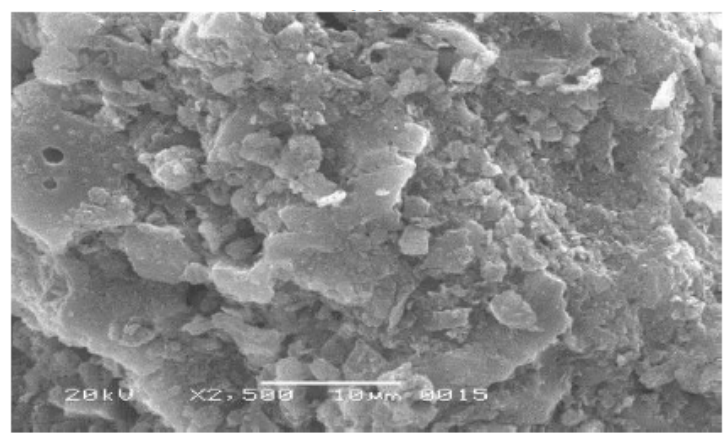

(b)

Figure 12: SEM image of lignite coal after reduction (a) $1 \mu \mathrm{m}$ (b) $10 \mu \mathrm{m}$.

\section{Electron Dispersion Spectroscopy (EDS) of Lignite Coal}

Figures 13(a, b) show EDS of lignite coal before and after oxidation. Figure 13(c) shows the EDS of lignite coal after reduction. Figure 14(a) shows that the 
mass percentage of oxygen had a noticeable increase after oxidation, from 32 to 37 . Hence, the overall percentage of carbon decreased, decreasing the carbon to oxygen ratio from 1.43 to 1.08 . Figure $\mathbf{1 4 ( b )}$ compares after oxidation and after reduction of subbituminous coal shows a decrease in oxygen content from 37 to 20 percent. Hence the overall percentage of carbon increased from 40 to 70 , noticeably increasing the carbon to oxygen ratio from 1.08 to 3.5 . There are still, however, silicon impurities but $\mathrm{GO}$ has been reduced to RGO [16, 20].

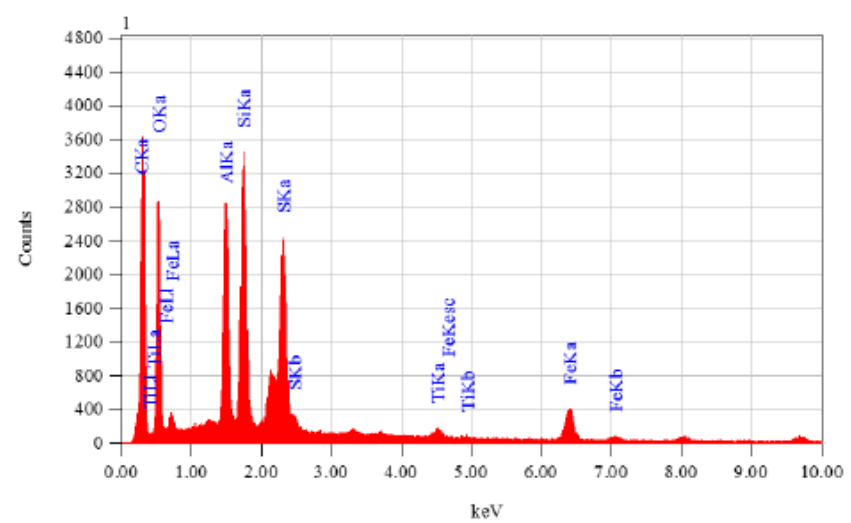

(a)

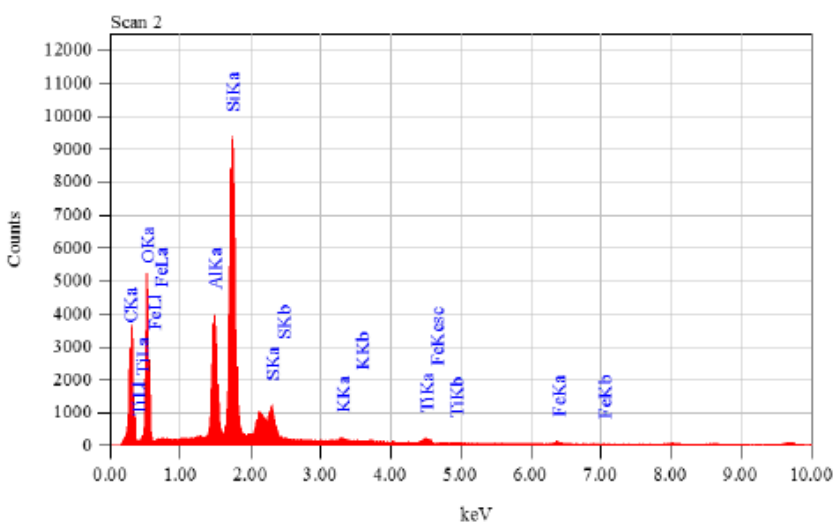

(b)

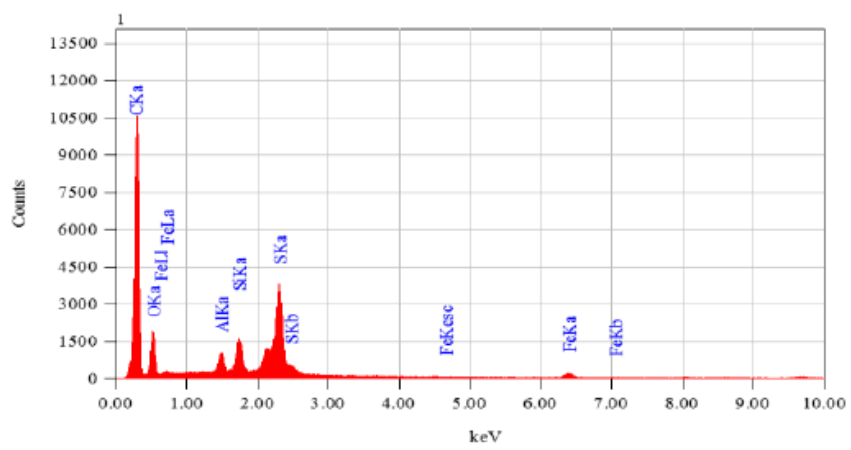

(c)

Figure 13: EDS of lignite coal (a) before oxidation (b) after oxidation (c) after reduction.

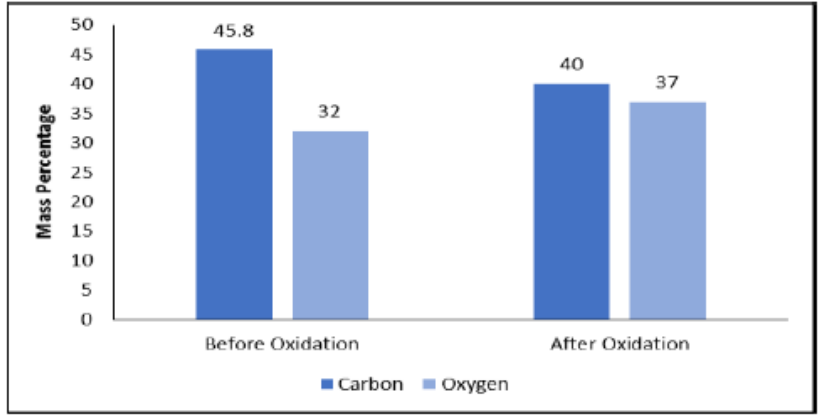

(a)

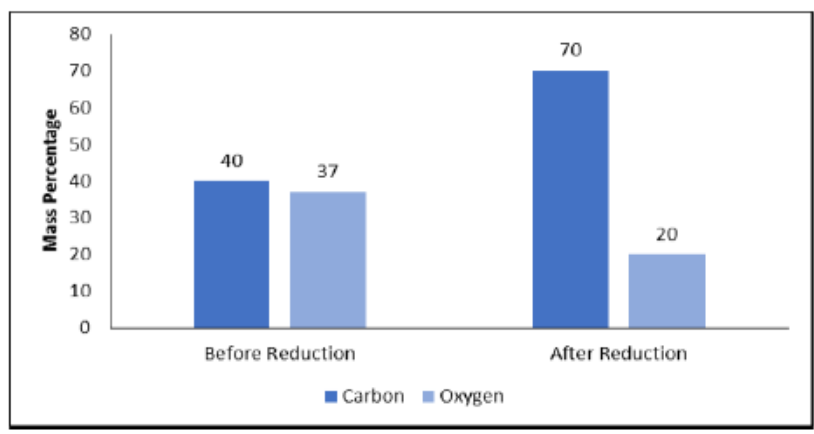

(b)

Figure 14: Mass percentage comparison of carbon and oxygen of lignite coal (a) before and after oxidation (b) before and after reduction.

\section{X-Ray Diffraction (XRD) of Lignite and Sub- bituminous Coal}

X-ray diffraction of lignite coal after oxidation and after reduction was performed, compared in Figure 15(a). The peak at $23^{\circ}$ has shifted to $27^{\circ}$ indicating interplanar spacing has reduced after reduction, and so the material has exfoliated. Another peek at around $12^{\circ}$ has appeared after the reduction, indicating graphene formation. Graphene is known to show a peak between $10-15^{\circ}$, and XRD analysis has confirmed that our sample is reduced graphene oxide showing similar characteristics to graphene; however, the peak is broad, which indicates that RGO produced is amorphous. The low-grade coal has used porous and could not produce very crystalline graphene-like, made from graphite $[9,12]$.

Figure 15(b) explains the effects of oxidation and reduction on sub-bituminous coal. A broad shoulder was observed in $\mathrm{GO}$ analysis from $15^{\circ}$ to $22^{\circ}$ indicating that the graphene oxide produced is amorphous. This shoulder after reduction shifted towards a higher degree, confirming that the material has exfoliated after reduction, and the $\mathrm{RGO}$ produced has smaller interplanar spacing than GO. There is a broad peak 
observed in RGO between $10^{\circ}$ to $15^{\circ}$, which alone confirms the resemblance of our sample with graphene. It can be established from the above XRD that the final product is amorphous reduced graphene oxide.

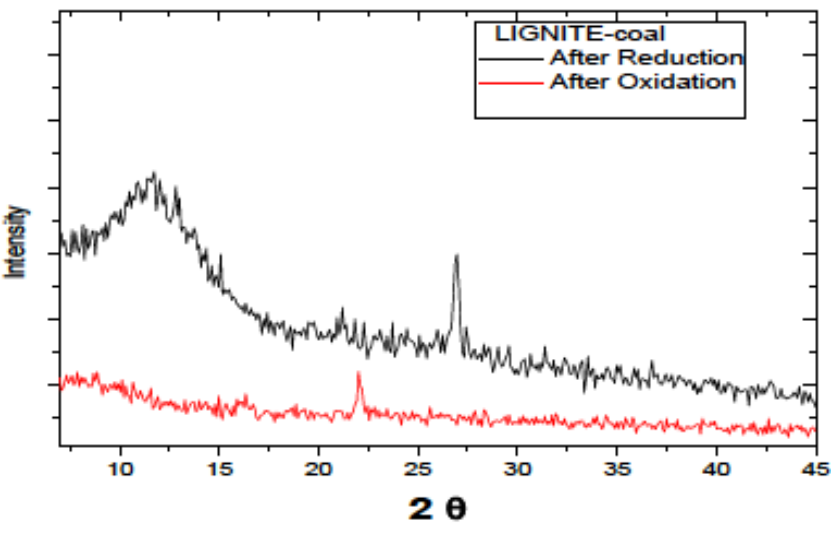

(a)

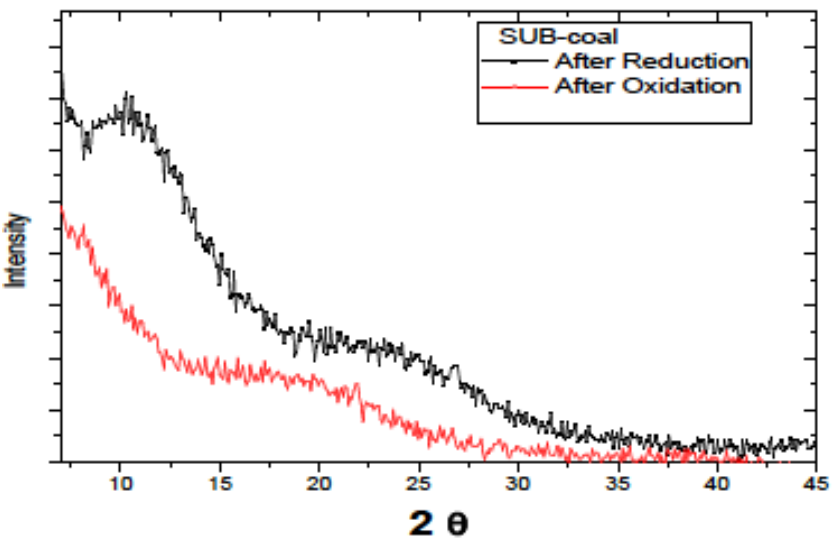

(b)

Figure 15: XRD after oxidation and reduction (a) lignite coal (b) sub-bituminous coal.

\section{Fourier Transform Infrared Spectroscopy (FTIR) of Graphene Oxide Before and After Reduction}

FTIR spectroscopy comparison of $\mathrm{GO}$ and RGO from sub-bituminous coal is shown in Figure 16. A broad dip was observed in $\mathrm{GO}$ at $3444 \mathrm{~cm}^{-1}$, which reduced in intensity after reduction. It indicates the presence of the $\mathrm{O}-\mathrm{H}$ (alcohol) group that has lessened in RGO, confirming that our sample has been reduced. Dips at $2925 \mathrm{~cm}^{-1}$ and $2855 \mathrm{~cm}^{-1}$ in both GO and RGO samples represent sp3 hybridized $\mathrm{C}-\mathrm{H}$ bonds that are the characteristic of graphene. Another dip at 1099 in $\mathrm{GO}$ is because of the $\mathrm{C}-\mathrm{O}$ bond, which has a high intensity in GO; however, it shortened in RGO, proving that the sample has been reduced [12, 24].

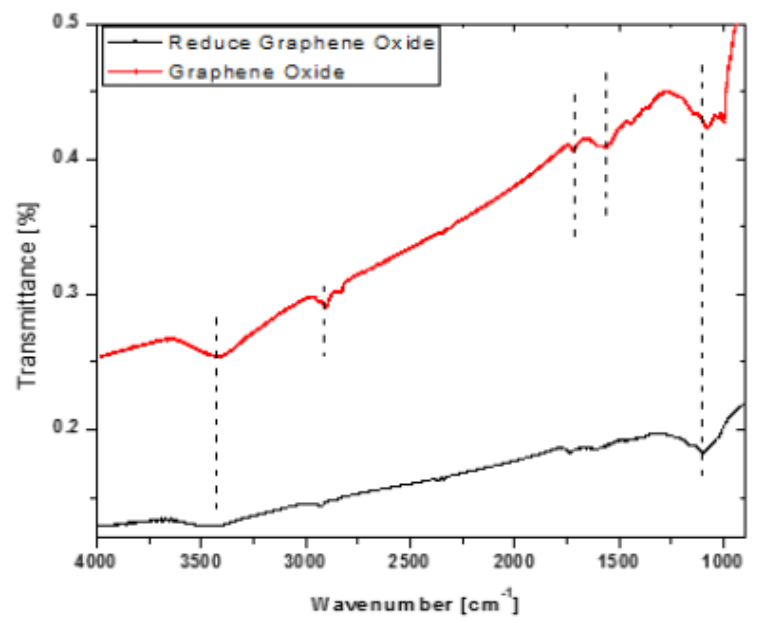

Figure 16: FTIR spectra of graphene oxide before and after reduction.

\section{CONCLUSION}

In the first phase, the pretreatment of coal has been accomplished. The carbon content of the pretreated coal has increased considerably, with the moisture and ash content being reduced. In the second phase, oxidation has been performed on both the subbituminous and lignite coal. Characterization of graphene oxide was also performed, showing positive results. The third phase, the reduction of graphene oxide to reduced graphene oxide (RGO), has also been completed. Both the sample from the lignite coal and the sample from the sub-bituminous coal has been reduced to RGO. The techniques that have been used to characterize this final sample include SEM, FTIR, and XRD. All of these confirm the formation of RGO, and so the last step was a success too. The final product, RGO, is closely related to graphene in structure and properties. Therefore, it is used in all the applications of graphene.

\section{ACKNOWLEDGMENT}

The authors would like to acknowledge the Department of Polymer and Petrochemical Engineering and, Department of Chemical Engineering NED University of Engineering \& Technology, Karachi, Pakistan, for supporting this research work.

\section{NOMENCLATURE}

\begin{tabular}{ll}
\hline \multicolumn{1}{c}{ Symbol } & \multicolumn{1}{c}{ Description } \\
\hline CVD & Chemical Vapor Deposition \\
\hline EDS & Energy Dispersive Spectroscopy \\
\hline FTIR & Fourier Transform Infrared Spectroscopic \\
\hline
\end{tabular}




\begin{tabular}{ll}
\hline GDP & Gross Domestic Product \\
\hline GNs & Graphene Nano-sheets \\
\hline GO & Graphene Oxide \\
\hline GONRs & Graphene Oxide Nano-ribbons \\
\hline IUPAC & $\begin{array}{l}\text { International Union of Pure and Applied } \\
\text { Chemistry }\end{array}$ \\
\hline LDH & Layered Double Hydroxides \\
\hline LPE & Liquid Phase Exfoliation \\
\hline MWCNTs & Multi-Walled Carbon Nanotubes \\
\hline RGO & Reduced Graphene Oxide \\
\hline RS & Raman spectroscopic \\
\hline SEM & Scanning Electron Microscopy \\
\hline TEM & Transmission Electron Microscopic \\
\hline XPS & X-ray Photo-electron Spectroscopic \\
\hline XRD & X-ray diffraction \\
\hline
\end{tabular}

[9]

Abd AA, Naji SZ, Hashim AS, Othman MR. Carbon dioxide removal through physical adsorption using carbonaceous and non-carbonaceous adsorbents: A review. J. Environ. Chem. Eng. 2020; 8: 1-23.

https://doi.org/10.1016/j.jece.2020.104142

[10] Wu Q, Sun C, Zhu ZZ, Wang YD, Zhang CY. Effects of Boron Carbide on Coking Behavior and Chemical Structure of High Volatile Coking Coal during Carbonization. Materials. 2021; 14: 1-12

https://doi.org/10.3390/ma14020302

[11] GhavamiNejad A, Hashmi S, Joh H-I, Lee S, Lee Y-S, Vatankhah-Varnoosfaderani $M$, et al. Network formation in graphene oxide composites with surface grafted poly- $\mathrm{N}$ isopropyl amide chains in aqueous solution characterized by rheological experiments. Phys. Chem. Chem. Phys. 2014; 16: 8675-85. https://doi.org/10.1039/C3CP55092C

, Wang $Y$, Zheng $H$, Wu Z X-ray absorption spectroscopy study on the thermal and hydrazine reduction of graphene oxide. J. Electron. Spectrosc. Relat. Phenom. 2014; 196: 89-93.

https://doi.org/10.1016/j.elspec.2013.10.011

[13] Powell C, Beall GW. Graphene oxide and graphene from low grade coal: Synthesis, characterization and applications. Curr. Opin. Colloid Interface Sci. 2015; 20: 362-6. https://doi.org/10.1016/j.cocis.2015.11.003

\section{REFERENCES}

[1] Zhou S, Guo P, Li J, Meng L, Gao H, Yuan X, et al. An electrochemical method for evaluation the cytotoxicity of fluorene on reduced graphene oxide quantum dots modified electrode. Sens. Actuators B Chem. 2018; 255: 2595-600. https://doi.org/10.1016/j.snb.2017.09.066

[2] Seevakan K, Manikandan A, Devendran P, Shameem A, Alagesan T. Microwave combustion synthesis, magnetooptical and electrochemical properties of $\mathrm{NiMoO} 4$ nanoparticles for supercapacitor application. Ceram. Int. 2018; 44: 13879-87. https://doi.org/10.1016/j.ceramint.2018.04.235

[3] Croitoru A, Oprea O, Nicoara A, Trusca R, Radu M, Neacsu I, et al. Multifunctional Platforms Based on Graphene Oxide and Natural Products. Medicina. 2019; 55: 1-22. https://doi.org/10.3390/medicina55060230

[4] Bora M, Benoy SM, Tamuly J, Saikia BK. Ultrasonic-assisted chemical synthesis of activated carbon from low-quality subbituminous coal and its preliminary evaluation towards supercapacitor applications. J. Environ. Chem. Eng. 2021; 9: $1-20$.

https://doi.org/10.1016/j.jece.2020.104986

[5] Liu S, Ge H, Wang C, Zou Y, Liu J. Agricultural waste/graphene oxide 3D bio-adsorbent for highly efficient removal of methylene blue from water pollution. Sci Total Environ. 2018; 628-629: 959-68.

https://doi.org/10.1016/j.scitotenv.2018.02.134

[6] Baig MM, Gul IH. Conversion of wheat husk to high surface area activated carbon for energy storage in highperformance supercapacitors. Biomass Bioenergy. 2021; 144: $1-8$. https://doi.org/10.1016/j.biombioe.2020.105909

[7] Iqbal S, Bibi I, Ata S, Kamal S, Ibrahim SM, Iqbal M. Gd and Co-substituted $\mathrm{LaNiO} 3$ and their nanocomposites with r-GO for photocatalytic applications. Diamond Relat. Mater. 2020; 110: 1-14. https://doi.org/10.1016/j.diamond.2020.108119

[8] Phounglamcheik A, Wang L, Romar H, Kienzl N, Broström M, Ramser $\mathrm{K}$, et al. Effects of Pyrolysis Conditions and Feedstocks on the Properties and Gasification Reactivity of Charcoal from Woodchips. Energy Fuels. 2020; 34: 8353-65. https://doi.org/10.1021/acs.energyfuels.0c00592
Awasthi S, Awasthi K, Ghosh AK, Srivastava SK, Srivastava ON. Formation of single and multi-walled carbon nanotubes and graphene from Indian bituminous coal. Fuel. 2015; 147: 35-42. https://doi.org/10.1016/j.fuel.2015.01.043

[15] Jia J, Zhang Y, Liu Q, Huang G, Xing B, Zhang C, et al. Characterization of coal-based humic acids in relation to their preparation methods. Energy Sourc A, Recovery Util. Environ. Effects. 2020; 42: 1-11. https://doi.org/10.1080/15567036.2020.1824034

[16] $\mathrm{Xu} \mathrm{H}$, Lin Q, Zhou T, Chen T, Lin S, Dong S. Facile preparation of graphene nano-sheets by pyrolysis of coal-tar pitch with the presence of aluminum. J Anal Appl. Pyrolysis. 2014; 110: 481-5.

https://doi.org/10.1016/j.jaap.2014.10.017

[17] Chang C-I, Chang K-H, Shen H-H, Hu C-C. A unique twostep Hummers method for fabricating low-defect graphene oxide nanoribbons through exfoliating multi-walled carbon nanotubes. J Taiwan Inst. Chem. Eng. 2014; 45: 2762-9. https://doi.org/10.1016/j.jtice.2014.05.030

[18] Kang JH, Kim T, Choi J, Park J, Kim YS, Chang MS, et al. Hidden Second Oxidation Step of Hummers Method. Chem. Mater. 2016; 28: 756-64. https://doi.org/10.1021/acs.chemmater.5b03700

[19] Wang K, Zhang X, Zhang X, Lin Q, Huang X. Preparation of fluffy graphene nano-sheets from coal-tar pitch with nano-A 203 as filler. J. Anal. Appl. Pyrolysis. 2016; 117: 354-6. https://doi.org/10.1016/j.jaap.2015.12.009

[20] Chen H, Gao H, Xiao H, Zhou X, Zhang W, Ling Q. Ecofriendly synthesis of few-layer graphene with high surface area under low temperature for supercapacitors. Electrochim. Acta. 2016; 206: 10-6. https://doi.org/10.1016/j.electacta.2016.04.141

[21] Ghorbani M, Abdizadeh H, Golobostanfard MR. Reduction of Graphene Oxide via Modified Hydrothermal Method. Procedia Mater. Sci. 2015; 11: 326-30. https://doi.org/10.1016/j.mspro.2015.11.104

[22] Duraia E-sM, Henderson B, Beall GW. Reduced humic acid nano-sheets and its uses as nanofiller. J. Phys. Chem. Solids. 2015; 85: 86-90. https://doi.org/10.1016/j.jpcs.2015.05.001

[23] Gurunathan S, Han JW, Kim ES, Park JH, Kim JH. Reduction of graphene oxide by resveratrol: a novel and simple 
biological method for the synthesis of an effective anticancer nanotherapeutic molecule. Int J. Nanomedicine. 2015; 10: 2951-69.

https://doi.org/10.2147//JN.S79879

[24] Fan X, Li S, Sun M, Song C, Xiao J, Du J, et al. Degradation of phenol by coal-based carbon membrane integrating sulfate radicals-based advanced oxidation processes. Ecotoxicol. Environ. Saf. 2019; 185: 1-6. https://doi.org/10.1016/i.ecoenv.2019.109662
[25] Alazmi A, Rasul S, Patole SP, Costa PMFJ. Comparative study of synthesis and reduction methods for graphene oxide. Polyhedron. 2016; 116: 153-61.

https://doi.org/10.1016/i.poly.2016.04.044

[26] Parvez K, Yang S, Feng X, Müllen K. Exfoliation of graphene via wet chemical routes. Synth. Met. 2015; 210: 123-32. https://doi.org/10.1016/j.synthmet.2015.07.014

Received on 27-11-2021

Accepted on 17-01-2022

Published on 22-01-2022

DOI: https://doi.org/10.15379/2410-1869.2022.09.01.01

(c) 2022 Hashmi et al.; Licensee Cosmos Scholars Publishing House.

This is an open access article licensed under the terms of the Creative Commons Attribution Non-Commercial License (http://creativecommons.org/licenses/by-nc/3.0/), which permits unrestricted, non-commercial use, distribution and reproduction in any medium, provided the work is properly cited. 